\title{
IMPACTOS DO DESMATAMENTO PROGRESSIVO DA AMAZÔNIA NA PRECIPITAÇÃO DO BRASIL
}

\author{
AMORIM, Tamiris Xavier - tamiris_xavier@id.uff.br \\ Universidade Federal Fluminense / UFF
}

SENNA, Mônica Carneiro Alves - monicasenna@id.uff.br
Universidade Federal Fluminense / UFF

CATALDI, Marcio - marcio.cataldi@gmail.com

Universidade Federal Fluminense / UFF

\begin{abstract}
RESUMO: A floresta amazônica possui importância indispensável para o equilíbrio climático terrestre, proporcionando inúmeros serviços ambientais, como a manutenção dos estoques de carbono e da ciclagem de água. O desmatamento é uma ameaça imediata ao bioma Amazônia, pois afeta os níveis de evapotranspiração da floresta, tornando o clima local mais quente e seco, influenciando no clima além de seus limites, devido à circulação atmosférica. Este estudo avalia os efeitos de longo prazo do desmatamento progressivo da Amazônia sobre a precipitação no Brasil, através do modelo CCM3-IBIS. Os resultados dos cenários de desmatamento indicaram anomalias negativas de precipitação com maior intensidade nos meses de setembro a novembro, afetando o regime de chuvas em grande parte das Regiões Norte, oeste da Região Nordeste e norte da Região Centro-Oeste, atingindo valores abaixo de $8 \mathrm{~mm} /$ dia sobre a Amazônia. Aproximadamente sobre as mesmas regiões onde foram simuladas anomalias negativas de precipitação também foram encontradas anomalias positivas de temperatura do ar à superfície, o que pode ser devido à redução da rugosidade superficial com o desmatamento, causando uma diminuição da evapotranspiração e alterando a forma como a superfície se resfria. Além disso, sobre essas regiões foram verificados uma redução da convergência dos ventos em $850 \mathrm{hPa}$ e um enfraquecimento da Alta da Bolívia em $200 \mathrm{hPa}$, desfavorecendo a atividade convectiva e a precipitação. Em contrapartida, nas Regiões Sudeste e Sul prevaleceram pequenas anomalias positivas de precipitação de até $2 \mathrm{~mm} / \mathrm{dia}$, e no extremo noroeste da América do Sul foram encontradas anomalias positivas de 2 a $4 \mathrm{~mm} / \mathrm{dia}$, especialmente no mês de outubro. Esse comportamento pode ser devido à redução da rugosidade superficial com o desmatamento, favorecendo um escoamento horizontal mais intenso do ar úmido oriundo do oceano Atlântico em $850 \mathrm{hPa}$, que ao encontrar a barreira orográfica dos Andes, gerou um aumento da precipitação sobre a região.
\end{abstract}

Palavras-chave: modelagem, mudanças climáticas, climatologia, CCM3-IBIS, floresta amazônica.

\section{IMPACTS OF THE AMAZON'S PROGRESSIVE DEFORESTATION IN THE PRECIPITATION OF} BRAZIL

ABSTRACT: The Amazon Rainforest has an indispensable importance for the terrestrial climate balance, providing numerous environmental services, such as the maintenance of the stocks of carbon and water cycling. Deforestation is an immediate threat to the Amazon biome, as it affects forest evapotranspiration levels, making the local climate warmer and drier, influencing the climate beyond its limits due to atmospheric circulation. This study evaluates the long-term effects of the progressive deforestation of the Amazon region on rainfall in Brazil, using the CCM3-IBIS model. The results of the deforestation scenarios indicated negative precipitation anomalies with higher intensity in the months of September to November, affecting the rainfall regime in most of the North, west of Northeast, and north of Central-West Regions, reaching values below $8 \mathrm{~mm} /$ day on the Amazon. Approximately above the same regions where negative precipitation anomalies were simulated, positive surface air temperature anomalies were also found, 
which may be due to the reduction of surface roughness with deforestation, causing a decrease in evapotranspiration and altering the way the surface cools. In addition, a reduction in the convergence of the winds at $850 \mathrm{hPa}$ and a weakening of the Bolivian High at $200 \mathrm{hPa}$ were observed on these regions, disfavoring the convective activity and the precipitation. On the other hand, positive anomalies of precipitation up to $2 \mathrm{~mm} /$ day prevailed in the Southeast and South Regions, and in the extreme north-west of South America positive anomalies of 2 to $4 \mathrm{~mm}$ /day were observed, especially in October. This behavior may be due to the reduction of surface roughness with deforestation, favoring a more intense horizontal flow of moist air from the Atlantic Ocean at $850 \mathrm{hPa}$, which, when encountering the orographic barrier of the Andes, generated an increase in precipitation over the region.

Keywords: modeling, climate change, climatology, CCM3-IBIS, amazon rainforest.

\section{INTRODUÇÃO}

A floresta amazônica é considerada a maior floresta tropical do planeta com uma área de aproximadamente 6,5 milhões de quilômetros quadrados. Seus rios contabilizam cerca de $20 \%$ das reservas de água doce do mundo e $60 \%$ de sua bacia hidrográfica localiza-se no território brasileiro, ocupando assim 49,29\% da extensão do Brasil, caracterizando o bioma Amazônia como o maior bioma brasileiro (IBGE, 2004).

Além de dispor da maior diversidade biológica do mundo (IBGE, 2004), a floresta amazônica possui importância indispensável para o equilíbrio climático terrestre, pois proporciona inúmeros serviços ambientais. Dentre os que mais influenciam nas mudanças climáticas ocorridas no Brasil e no mundo, estão o grande poder de armazenamento de carbono e os efeitos sobre o ciclo hidrológico (ARTAXO et al., 2014).

Levando em consideração a bacia amazônica, estudos comprovam que a área é capaz de transpirar 20 bilhões de toneladas de água por dia (ou 20 trilhões de litros) (NOBRE, 2014). E ainda que o vapor d'água contribua com apenas $2 \%$ da massa total da atmosfera, este é considerado por alguns autores como o mais importante componente para a definição do tempo e do clima (AYOADE, 2010). Segundo Nobre et al. (2009a), a Amazônia caracteriza um importante regulador do clima global devido a sua vasta dimensão e localização próxima ao Equador, sendo esta uma relevante fonte de vapor d'água para todo o sistema climático.

Estudos realizados pelo Instituto Nacional de Pesquisas Espaciais (INPE), através do Projeto de Monitoramento da Floresta Amazônica Brasileira por Satélite (PRODES), computaram uma taxa de desmatamento equivalente a $5.012 \mathrm{Km}^{2}$ no ano de 2014 , o que demonstrou uma redução de $15 \%$ em relação às taxas do ano anterior $\left(5.891 \mathrm{Km}^{2}\right)$. Já no ano de 2015 , o estudo estimou um aumento de $16 \%$ em relação ao ano anterior, representando a eliminação de $5.831 \mathrm{Km}^{2}$ de floresta (INPE, 2016). Tais resultados comprovam o constante desequilíbrio no controle do desmatamento da floresta amazônica, que resultam na perda de milhares de quilômetros quadrados de vegetação a cada ano.

As mudanças climáticas são uma ameaça para o bioma amazônico em longo prazo, devido às alterações causadas na dinâmica do sistema local. Contudo, o desmatamento é uma ameaça imediata, pois afeta diretamente os níveis de evapotranspiração da floresta, tornando o clima local mais quente e seco e podendo influenciar no clima de regiões distantes da própria Amazônia, devido à circulação atmosférica (MARENGO et al., 2011). 
Diversas pesquisas projetam, através de modelagem climática, os impactos que o desmatamento progressivo da floresta amazônica pode causar no clima local e remoto. Os resultados de Correia et al. (2008) e Artaxo et al. (2014) permitiram observar um aumento na precipitação local quando foram criados cenários de desmatamento parcial, contudo, ao simular um desmatamento maior, notou-se um clima mais seco, com redução na precipitação local. Lejeune et al. (2015) e Llopart et al. (2018) encontraram um padrão dipolar da precipitação em resposta ao desmatamento amazônico, indicando decréscimo da precipitação no setor oeste e um acréscimo no setor leste da Bacia Amazônica. Entretanto, Silva et al. (2016) verificaram um padrão de precipitação dipolar oposto, onde o oeste (leste) amazônico tornava-se mais úmido (seco). Gedney e Valdes (2000) constataram alterações no clima de regiões distantes da área desmatada na Amazônia, como variações na precipitação no nordeste do Atlântico, estendendo-se para o oeste da Europa, durante o inverno. Werth e Avissar (2002) verificaram que o desmatamento amazônico reduziu significativamente a precipitação na América do Norte, entretanto, em regiões mais distantes dos trópicos, os sinais desta teleconexão se enfraqueciam.

Segundo Correia et al. (2007), estudos observacionais mostraram que em áreas de pastagem há uma menor absorção de radiação solar à superfície e uma redução da evapotranspiração e da umidade do ar. Os autores também destacaram a importância da floresta para a circulação de umidade na região, a qual uma parte é processada pela evapotranspiração e a outra é importada do Oceano Atlântico. Tal processo faz com que a Amazônia exporte em direção ao Sul da América do Sul, Oceano Pacífico e Caribe, uma porção anual de vapor d'água de aproximadamente quatro vezes a sua evapotranspiração. Fearnside (2006) destaca a importância da ciclagem da água realizada na Amazônia e exportada para outras regiões do Brasil e para países adjacentes. Parte desta água consegue ultrapassar os Andes, porém, sua maior parcela é desviada para o Sul quando encontra a barreira andina. Nesse caminho, quando direcionada mais especificamente para a região Sudeste do Brasil, a chuva que cai abastece os principais reservatórios hidrelétricos, como também os que são usados como fontes de água potável nas principais e mais populosas regiões do país. Fatos como estes levam a deduzir a existência de sérios problemas sociais caso haja uma significativa redução nesse transporte de vapor d'água.

O conhecimento prévio de possíveis mudanças no clima do território brasileiro em função do desmatamento progressivo da Amazônia possui, além da importância científica, grande relevância social. Tal estudo pode contribuir para a criação de políticas públicas de estratégia e educação ambiental, que visam a recuperação de áreas degradadas, melhorias no gerenciamento dos recursos hídricos, metodologias de prevenção à seca e inundações e, além disso, uma melhor compreensão do papel da floresta amazônica na regulação e no equilíbrio de padrões climáticos do Brasil.

Dado o exposto, este estudo teve como objetivo avaliar os efeitos de longo prazo do desmatamento progressivo da Amazônia sobre a precipitação no Brasil. Tal objetivo foi atingido através do uso do Community Climate Model, version 3 - Integrated Biosphere Simulator (CCM3-IBIS), um modelo climático global acoplado a um modelo de vegetação dinâmica (Delire et al., 2003). 


\section{MATERIAL E MÉTODOS}

A presente pesquisa fez uso do sistema de modelagem climática CCM3IBIS, que funciona com dois modelos acoplados (DELIRE et al., 2003). O CCM3 é um modelo de circulação geral da atmosfera, desenvolvido pela Divisão de Clima e Dinâmica Global do National Center for Atmospheric Research (NCAR) (KIEHL et al., 1998), que simula a física em grande escala (transferência radiativa, ciclo hidrológico, desenvolvimento de nuvens, termodinâmica) e a dinâmica da atmosfera (SENNA et al., 2009a). Nesse modelo o mundo é dividido em grades com células, a partir das quais são realizados cálculos matemáticos baseados em leis da física e levando em consideração as forçantes externas, como por exemplo, a energia solar, simulando assim o sistema climático (BETTS et al., 2011). Para a elaboração dos cálculos deste estudo foram levadas em consideração apenas as células de grade que cobrem o território brasileiro, como ilustra a Figura 1.

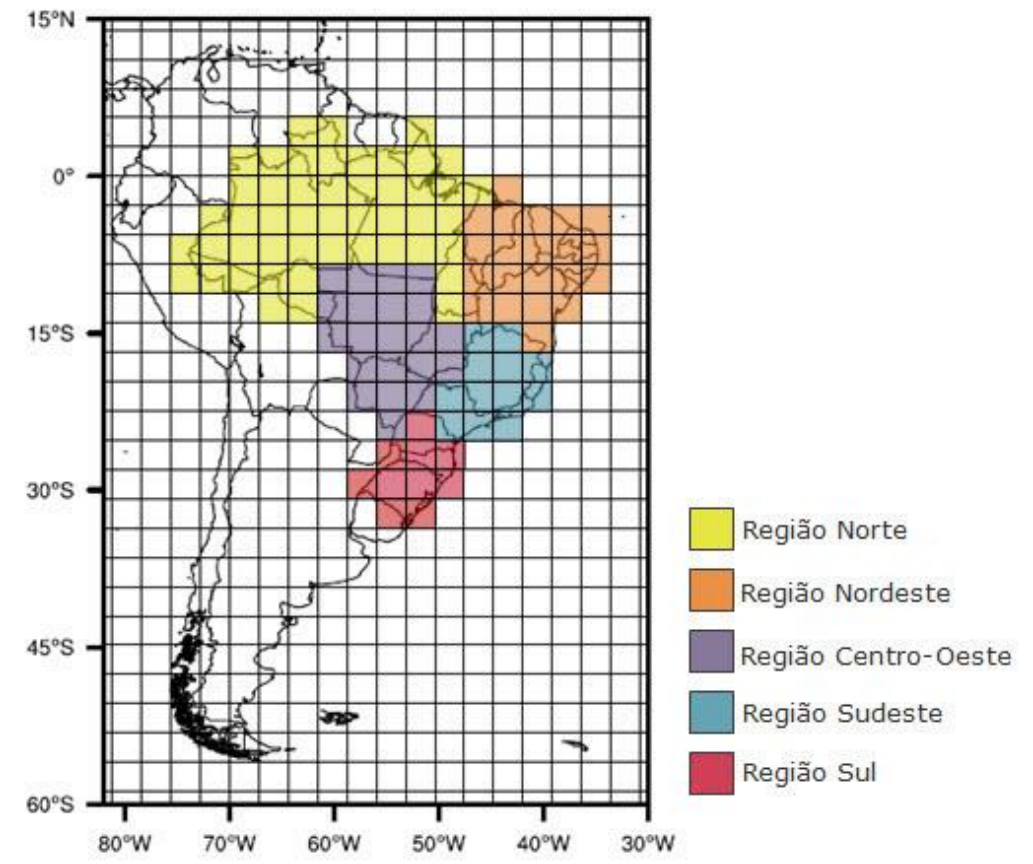

Figura 1 - Representação da grade do CCM3-IBIS, com as células coloridas de acordo com cada região brasileira considerada.

Já o IBIS é um modelo da vegetação global que abrange processos dinâmicos da biosfera terrestre. Representa processos biofísicos, fisiológicos e ecológicos da vegetação e do solo, simulando as trocas de energia, água, carbono e momentum no sistema solo-vegetação-atmosfera, considerando, assim, as mudanças na estrutura e composição da vegetação, causadas pelas condições ambientais (FOLEY et al., 1996, SENNA et al., 2009a). Esse modelo reproduz um sistema complexo e com riqueza de detalhes, possibilitando a simulação de uma cobertura vegetal dinâmica, na qual a vegetação pode ser modificada de acordo com as condições climáticas simuladas durante a integração do modelo (CHOU e NOBRE, 2014). O IBIS calcula em cada célula de grade duas camadas de vegetação: "árvores" e "gramíneas e arbustos". Este considera seis camadas de solo para simular a temperatura e o conteúdo de 
água existente. A cobertura da vegetação é representada como um conjunto de doze Tipos Funcionais de Planta (TFP), em que cada tipo é caracterizado em termos de biomassa (carbono nas folhas, troncos e raízes finas) e índice de área foliar. Os TFP se diferem com relação à forma (árvores ou gramíneas ou arbustos), comportamento das folhas (perenifólias ou caducifólias), forma das folhas (folhas largas ou aciculadas) e fisiologia (C3 ou C4). Um ponto de grade pode conter um ou mais TFP que, juntos, abrangem um dentre os quinze tipos de vegetação (FOLEY et al., 1996).

Os dois sistemas acoplados permitem a simulação das interações atmosfera-biosfera, resolvendo numericamente as interações biofísicas de curto prazo entre a superfície e a atmosfera através das trocas de energia, água, carbono e momentum; e as retroalimentações de longo prazo entre a vegetação e o clima, gerando mudanças na cobertura vegetal e nos reservatórios de carbono (PEREIRA, 2006). Segundo Senna et al. (2009b), este modelo simula claramente o clima médio dentro de uma faixa de erro de $7 \%$.

Contudo, ainda não é possível reproduzir exatamente todos os detalhes do mundo real em um modelo climático, sendo necessária a inclusão de configurações aproximadas, determinadas com estudos específicos. Tais configurações podem influenciar nos resultados do modelo quando somadas a outras variáveis que não podem ser previstas com exatidão, como por exemplo, a concentração de gases de efeito estufa, contribuindo para as incertezas das projeções futuras (BETTS et al., 2011).

Neste estudo o CCM3-IBIS foi utilizado com resolução espectral T42 $\left(\sim 2,8^{\circ} \times 2,8^{\circ}\right)$, vegetação dinâmica e integrado por 50 anos. Em todas as simulações a concentração atmosférica de gás carbônico foi mantida constante, em 380 partes por milhão por volume (ppmv), e a temperatura da superfície do mar foi considerada fixa para cada mês do ano, de acordo com a climatologia elaborada por Shea et al. (1992). Nas simulações que consideraram o desmatamento, a produção primária líquida ( $P P L)$ da floresta foi reduzida conforme estudo realizado por Senna (2008), de acordo com uma relação empírica que produz um decréscimo de $50 \%$ da PPL para a biomassa das árvores igual a zero, e nenhum decréscimo da PPL quando a biomassa das árvores atinge $10 \mathrm{~kg}-\mathrm{C} \mathrm{m} \mathrm{m}^{-2}$ ou mais (valores típicos de uma floresta madura). Essa relação empírica reproduz eventuais efeitos que a redução na ciclagem de nutrientes no solo teria no recrescimento da floresta (DAVIDSON et al., 2004; ZARIN et al., 2005).

Inicialmente foi realizada a simulação controle, considerando $100 \%$ da cobertura inicial do solo na região amazônica como floresta tropical. Posteriormente, foram realizadas novas simulações, nas quais a floresta passou a ser representada com níveis de 20\% (P20), 60\% (P60) e 100\% (P100) da cobertura inicial do solo transformada em pastagem, baseado nos cenários de desmatamento elaborados por Soares-Filho et al. (2006), como ilustra a Figura 2. 
Controle

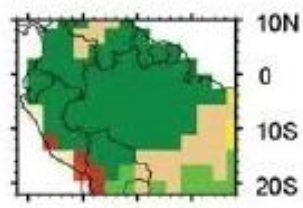

P20

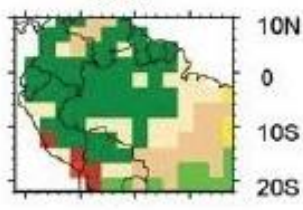

P60

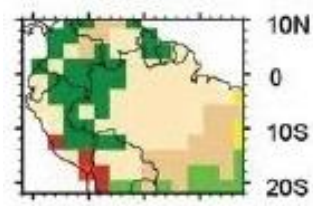

P100

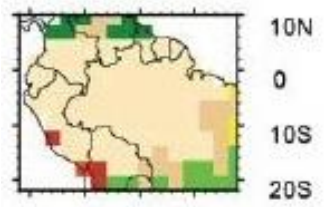

80W 70W 60W 50W
Deserto

Tundra

Caatinga

Pastagem

Cerrado

Floresta Decidua

Floresta Tropical

Figura 2 - Cobertura inicial do solo da Floresta Amazônica considerada nas simulações Controle, P20, P60 e P100.

\section{RESULTADOS E DISCUSSÃO}

Após realizar a simulação controle, considerando $100 \%$ da cobertura inicial do solo na região amazônica como floresta tropical, e as simulações de desmatamento, considerando $20 \%, 60 \%$ e $100 \%$ da cobertura inicial do solo transformada em pastagem, os valores e as anomalias de precipitação total média referente aos 50 anos de integração do modelo para cada cenário foram compilados em gráficos e mapas contendo as simulações de cada caso e as diferenças entre os casos forçados com o desmatamento e o caso controle (Figuras 3 a 8), que considera a cobertura original na região da floresta, conforme a vegetação potencial global elaborada por Ramankutty e Foley (1999).

Na Região Norte observou-se redução nos totais de precipitação na maior parte do ano, sendo tal evento mais influente nos meses de agosto a novembro, em todos os cenários de desmatamento, havendo queda entre $-0,70$ e $-3,30$ $\mathrm{mm}$ /dia aproximadamente (Figura 3). Além disso, os resultados mostraram que quanto maior era a área transformada em pastagem, maior era a intensidade e a área atingida pela redução das chuvas anualmente (Figura 8 ). 
A Região Nordeste apresentou redução na precipitação na maioria dos meses, porém de forma mais acentuada em novembro e dezembro, expressando no mês de dezembro as maiores anomalias negativas, 1,26 e 1,11 $\mathrm{mm}$ /dia nos cenários P60 e P100, respectivamente (Figura 4). Embora nos cenários P20 e P60 seja possível perceber que a área desmatada possuiu forte influência sobre os totais pluviométricos, o cenário P100 demonstrou que o impacto do desmatamento não foi linear, contabilizando uma anomalia negativa anual $(0,29 \mathrm{~mm} / \mathrm{dia})$, que foi menor que a do cenário P60 (0,32 mm/dia), resultado este (Tabela 1 ) que pode ser explicado pela regeneração florestal, demonstrada adiante.

No Centro-Oeste brasileiro houve uma maior redução da precipitação nos meses de setembro a novembro, período em que as anomalias negativas variaram entre 1,00 e 2,80 mm/dia. Nesta região o cenário P60 apresentou o menor impacto sobre a precipitação anual, seguido do P20 e P100 (Figura 5 e Tabela 1).

Já as Regiões Sudeste (Figura 6) e Sul (Figura 7) não sofreram impactos consideráveis nos totais pluviométricos durante todo 0 ano, devido ao desmatamento amazônico. Embora tenham sido computadas anomalias negativas em alguns meses em todos os cenários, anualmente prevaleceu uma anomalia positiva com pequenas variações, atingindo valores entre 0,08 e 0,20 $\mathrm{mm} /$ dia (Tabela 1).

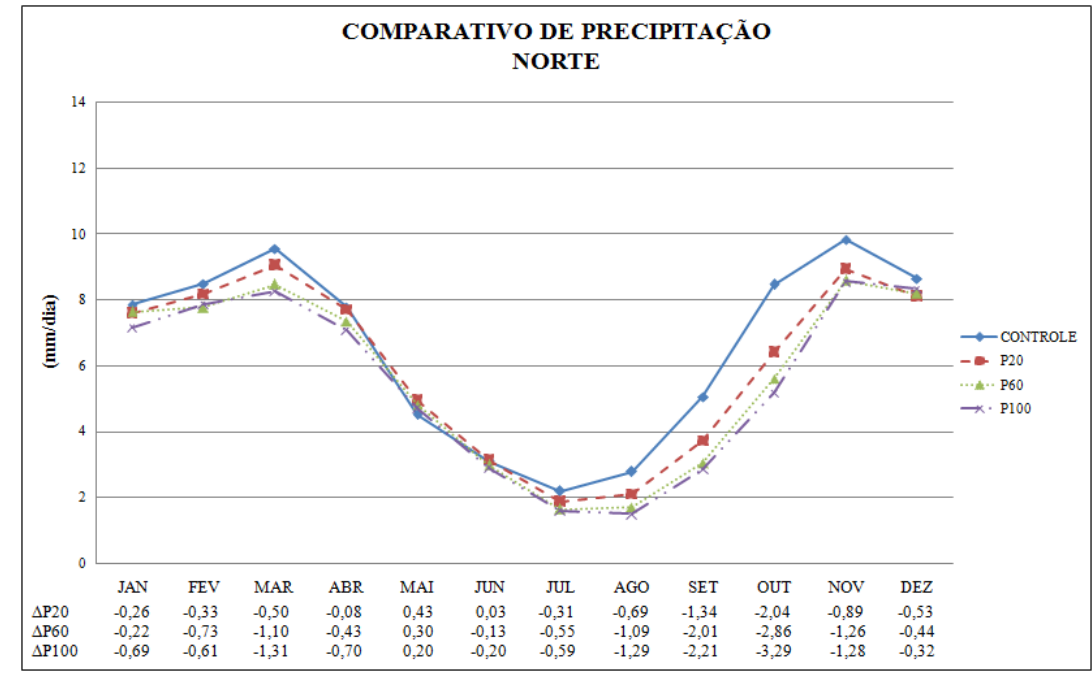

Figura 3 - Precipitação total mensal média ( $\mathrm{mm} / \mathrm{dia}$ ) referente aos 50 anos de integração do modelo para a Região Norte considerando os cenários Controle, P20, P60 e $\mathrm{P} 100$, e as anomalias da precipitação média mensal de cada cenário de desmatamento. 


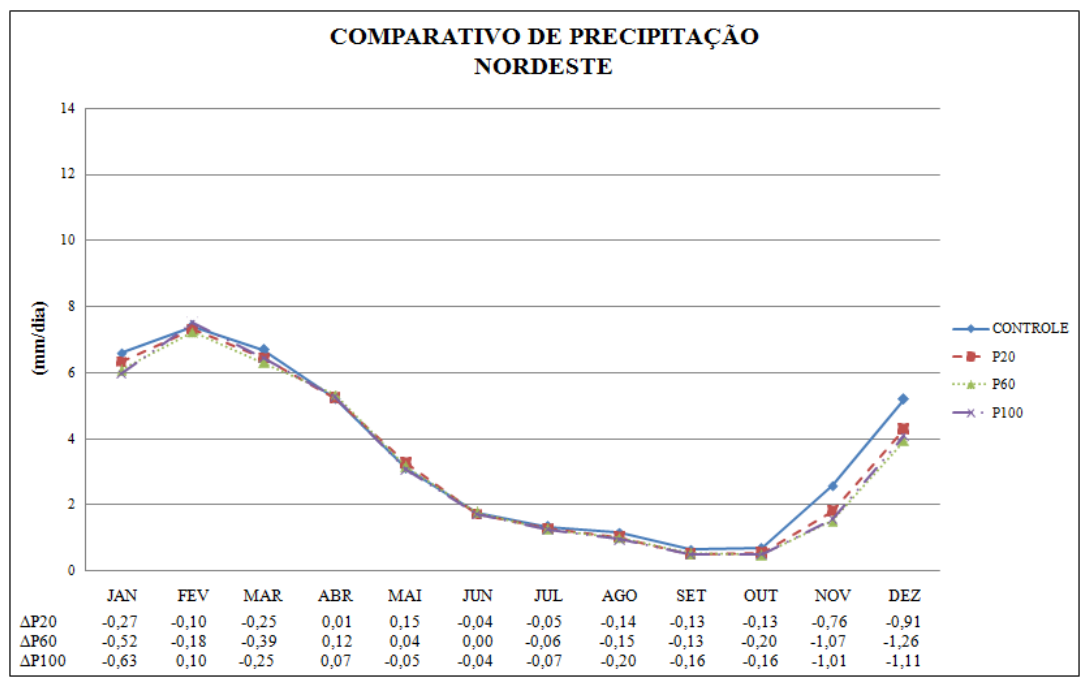

Figura 4 - Precipitação total mensal média $(\mathrm{mm} / \mathrm{dia})$ referente aos 50 anos de integração do modelo para a Região Nordeste considerando os cenários Controle, P20, P60 e P100, e as anomalias da precipitação média mensal de cada cenário de desmatamento.

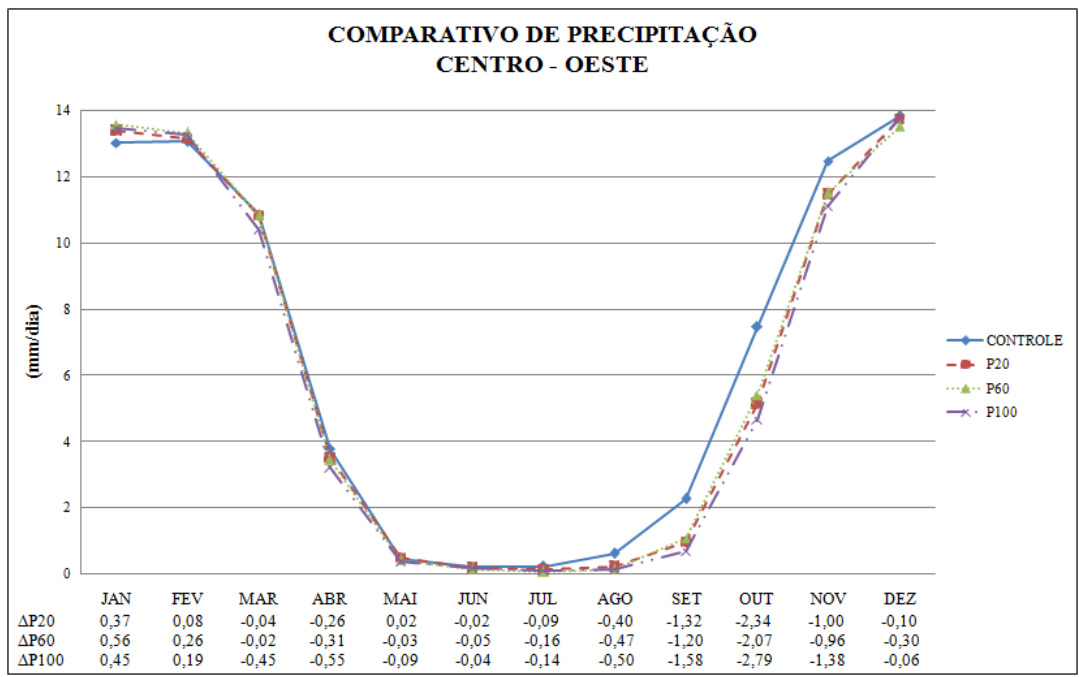

Figura 5 - Precipitação total mensal média $(\mathrm{mm} / \mathrm{dia})$ referente aos 50 anos de integração do modelo para a Região Centro-Oeste considerando os cenários Controle, P20, P60 e P100, e as anomalias da precipitação média mensal de cada cenário de desmatamento. 


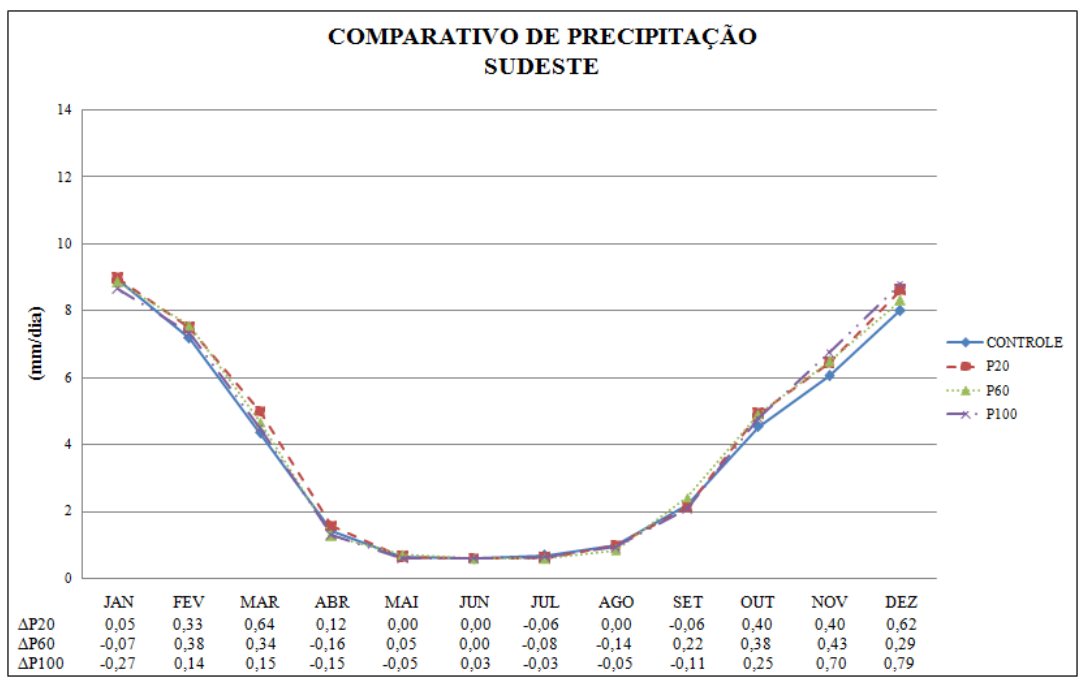

Figura 6 - Precipitação total mensal média $(\mathrm{mm} / \mathrm{dia})$ referente aos 50 anos de integração do modelo para a Região Sudeste considerando os cenários Controle, P20, P60 e P100, e as anomalias da precipitação média mensal de cada cenário de desmatamento.

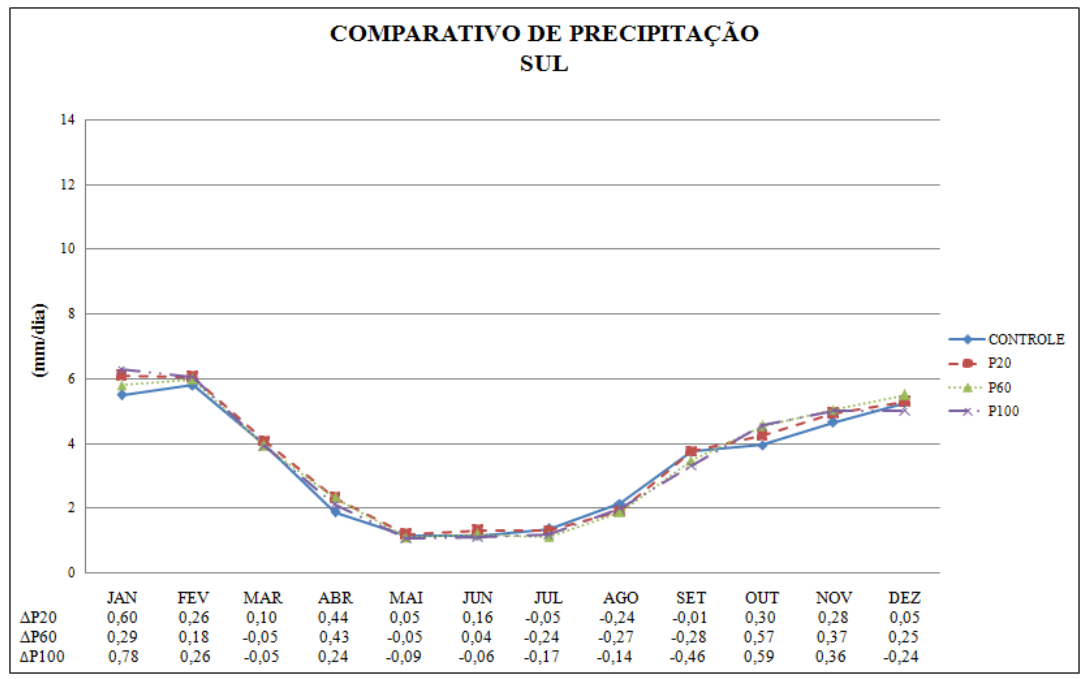

Figura 7 - Precipitação total mensal média ( $\mathrm{mm} / \mathrm{dia}$ ) referente aos 50 anos de integração do modelo para a Região Sul considerando os cenários Controle, P20, P60 e P100, e as anomalias da precipitação média mensal de cada cenário de desmatamento.

Tabela 1 - Anomalia da precipitação total anual média ( $\mathrm{mm} / \mathrm{dia})$ referente aos 50 anos de integração do modelo.

\begin{tabular}{lccc}
\hline & $\mathbf{\Delta P 2 0}$ & $\mathbf{\Delta P 6 0}$ & $\mathbf{\Delta P 1 0 0}$ \\
\hline NORTE & $-0,54$ & $-0,88$ & $-1,03$ \\
NORDESTE & $-0,22$ & $-0,32$ & $-0,29$ \\
CENTRO-OESTE & $-0,42$ & $-0,40$ & $-0,58$ \\
SUDESTE & 0,20 & 0,14 & 0,12 \\
SUL & 0,16 & 0,10 & 0,08 \\
\hline
\end{tabular}


A Figura 8 ilustra a distribuição média mensal da anomalia de precipitação (cenário desmatamento - cenário controle) sobre o Brasil, permitindo uma melhor visualização da dimensão e intensidade dos impactos causados pelo desmatamento da Floresta Amazônica. Percebe-se que a localização da Floresta Amazônica está diretamente relacionada às áreas com anomalias negativas, que chegaram a alcançar valores abaixo de $-8 \mathrm{~mm} / \mathrm{dia}$ nos meses de setembro a novembro, porém tais áreas de anomalias se expandiram para regiões adjacentes e se intensificaram à medida que os cenários de desmatamento tornavam-se mais críticos, atingindo, de maneira geral, a Região Norte, oeste da Região Nordeste e norte da Centro-Oeste. Em contrapartida, observa-se que as anomalias positivas de no máximo $2 \mathrm{~mm} / \mathrm{dia}$ se concentraram, em geral, na Região Sudeste, sul da Região Centro-Oeste e norte da Região Sul. Além disso, é notável uma área de anomalias positivas, entre 2 e $4 \mathrm{~mm} /$ dia, no extremo noroeste da América do Sul, principalmente durante outubro. Os possíveis mecanismos causadores das anomalias negativas e positivas de precipitação serão investigados nos próximos parágrafos, com a análise de outras variáveis meteorológicas, como a temperatura e o escoamento horizontal do ar. 


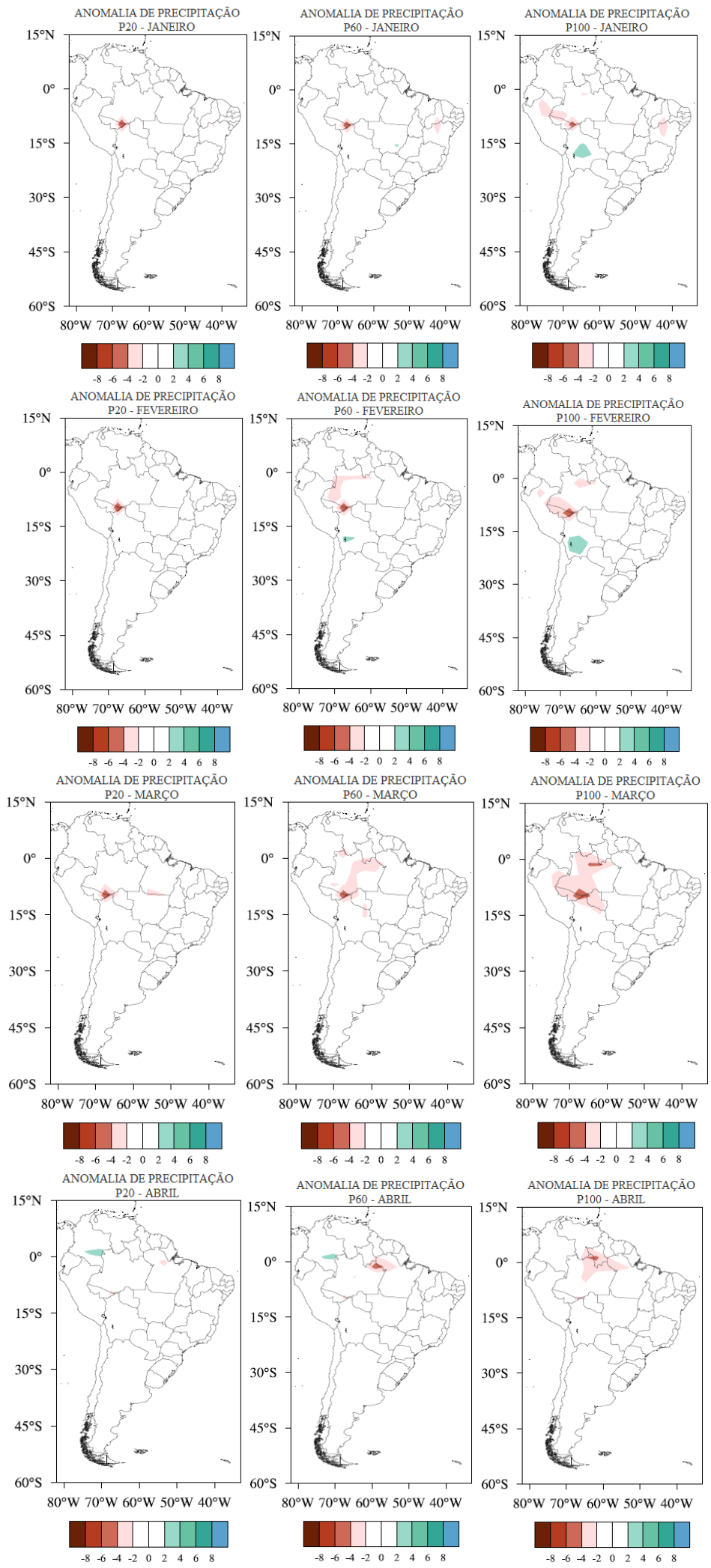

Figura 8 - Mapas de anomalia de precipitação total mensal média ( $\mathrm{mm} / \mathrm{dia}$ ) referente aos 50 anos de integração do modelo dos cenários P20, P60 e P100 em relação à simulação Controle. (Continua) 

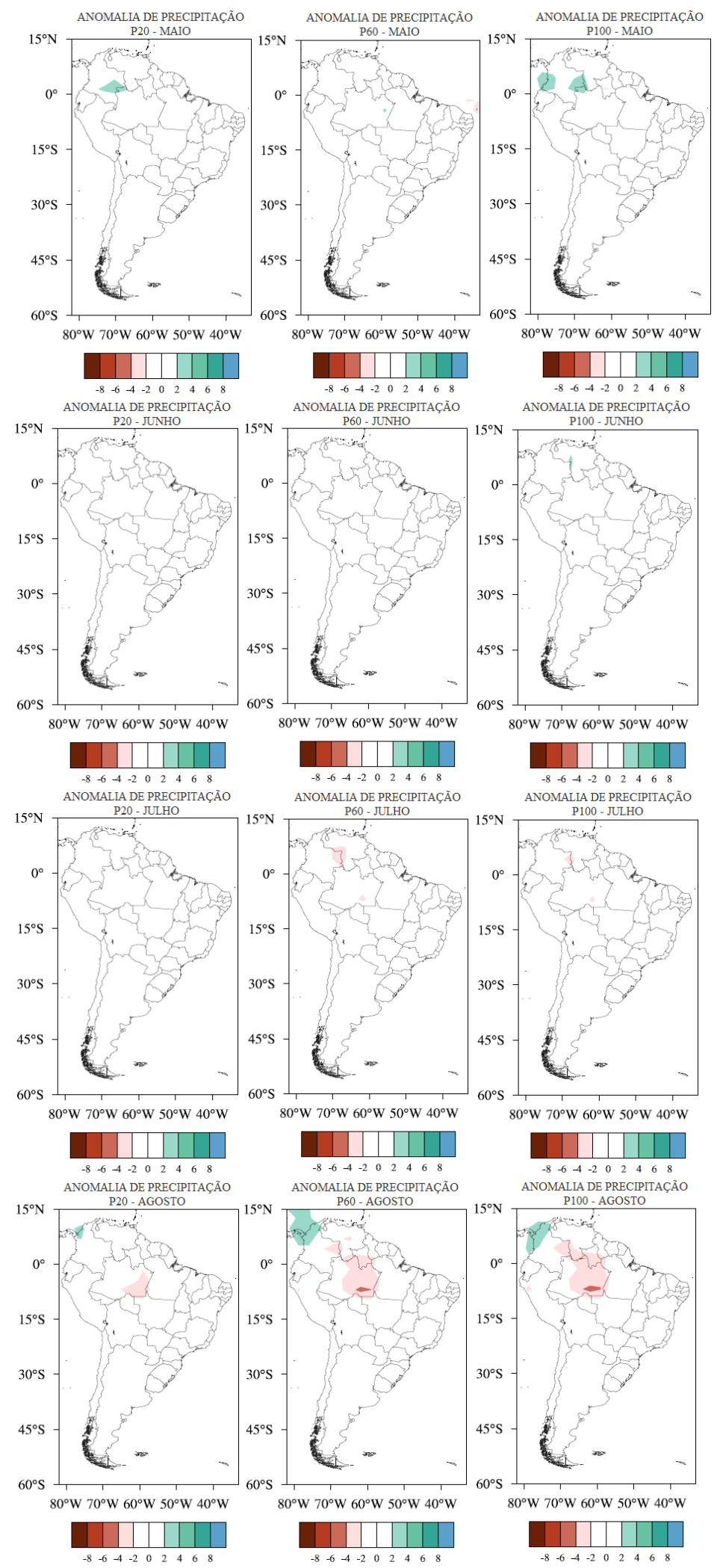

Continuação Figura 8 - Mapas de anomalia de precipitação total mensal média $(\mathrm{mm} / \mathrm{dia})$ referente aos 50 anos de integração do modelo dos cenários P20, P60 e P100 em relação à simulação Controle. (Continua) 

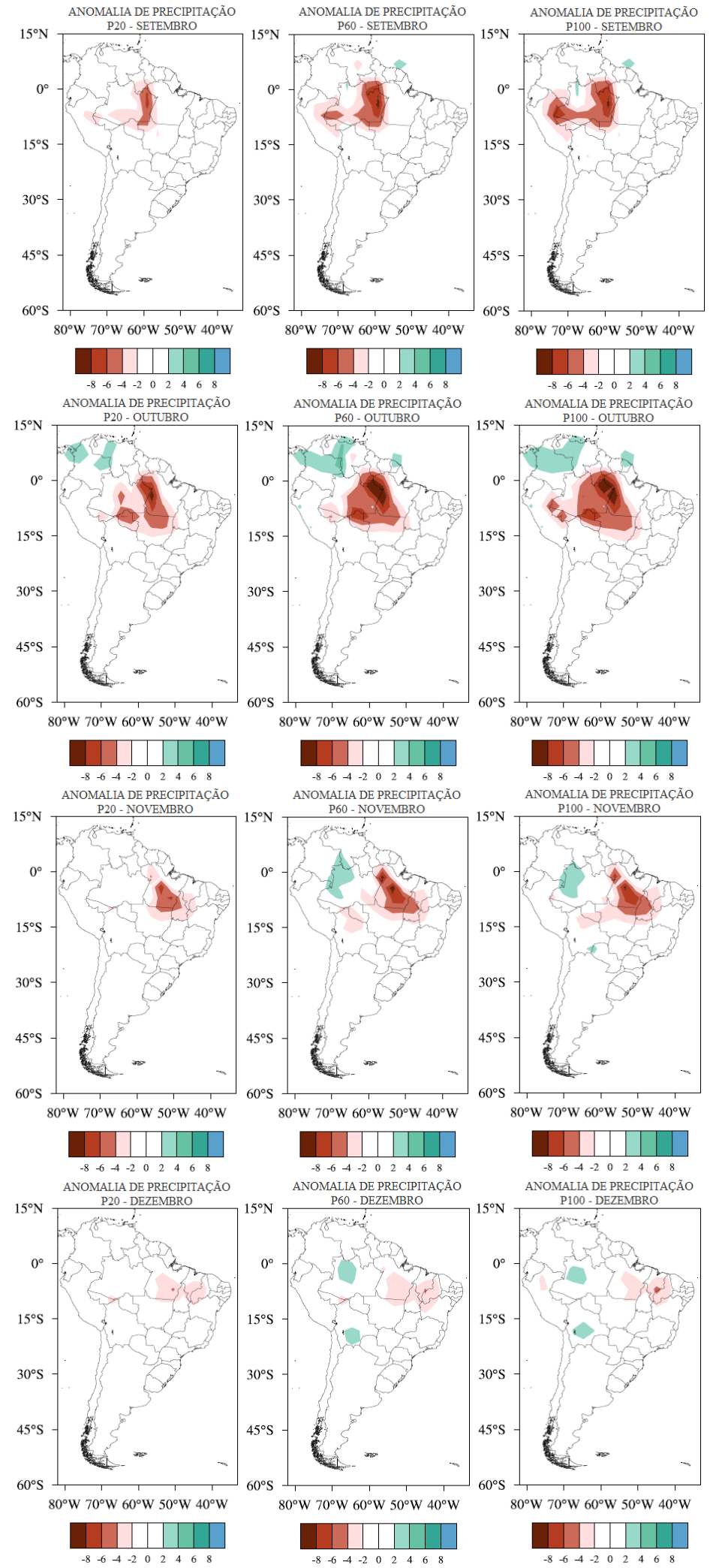

$80^{\circ} \mathrm{W} 70^{\circ} \mathrm{W} 60^{\circ} \mathrm{W} 50^{\circ} \mathrm{W} 40^{\circ} \mathrm{W}$

Continuação Figura 8 - Mapas de anomalia de precipitação total mensal média $(\mathrm{mm} / \mathrm{dia})$ referente aos 50 anos de integração do modelo dos cenários P20, P60 e P100 em relação à simulação Controle. (Conclusão) 
A Tabela 2, adaptada de estudo realizado por Lejeune et al. (2015), resume as características e alguns resultados encontrados em diversas pesquisas em que foi feito o uso de modelos climáticos globais para simular um cenário de desmatamento total da floresta amazônica. Esta Tabela demonstra somente o impacto gerado sobre a Região Norte do Brasil e, embora os estudos tenham sido realizados com modelos, resoluções, entre outras características e especificações diferentes, de maneira geral, alguns resultados são próximos entre si. Em relação à precipitação média anual, este estudo simulou uma redução nesta variável $(-1,03 \mathrm{~mm} / \mathrm{dia})$, a média de todos os outros estudos desta Tabela foi $-0,78 \mathrm{~mm} / \mathrm{dia}$. Ao analisar caso a caso, percebeu-se a semelhança com outros resultados, destacando-se Lean e Warrilow (1989) ( 1,34 mm/dia), Dickinson e Kennedy (1992) $(-1,4 \mathrm{~mm} /$ dia), Lean e Rowntree (1993) ( 0,81 mm/dia), Sud et al. (1996) $(-1,48 \mathrm{~mm} / \mathrm{dia})$, Zhang et al. (1996) $(-1,1 \mathrm{~mm} / \mathrm{dia})$, Hahmann e Dickinson (1997) $(-0,99 \mathrm{~mm} / \mathrm{dia})$, Costa e Foley (2000) $(-0,73 \mathrm{~mm} /$ dia), Gedney e Valdes (2000) $(-0,79 \mathrm{~mm} /$ dia), Voldoire e Royer (2005) (-0,74 mm/dia) e Ramos da Silva et al. (2008) $(-1,24 \mathrm{~mm} / \mathrm{dia})$. Além disso, este estudo apresentou uma média anual de elevação da temperatura do ar à superfície relativamente baixa $\left(+0,28^{\circ} \mathrm{C}\right)$ se comparada à média encontrada nos demais estudos da Tabela (aproximadamente $+1,36^{\circ} \mathrm{C}$ ). Analisando individualmente, percebeu-se a proximidade com os resultados encontrados por Dickinson e Kennedy (1992) $\left(+0,6{ }^{\circ} \mathrm{C}\right)$, Henderson-Sellers et al. (1993) $\left(+0,6^{\circ} \mathrm{C}\right)$, Zhang et al. (1996) $\left(+0,3^{\circ} \mathrm{C}\right)$, Voldoire e Royer (2005) $\left(+0,6^{\circ} \mathrm{C}\right)$ e Costa $(2016)\left(+0,14^{\circ} \mathrm{C}\right)$. A temperatura do ar à superfície simulada será descrita com maiores detalhes adiante, para explicar alguns comportamentos observados na precipitação total simulada.

Tabela 2 - Comparação de estudos realizados com modelos climáticos globais, para um cenário de desmatamento total na região amazônica. Onde: $\Delta T$ representa a anomalia da temperatura do ar na superfície anual em ${ }^{\circ} \mathrm{C}, \Delta \mathrm{P}$ a anomalia da precipitação total anual em mm/dia, e "ni" não informado. Fonte: Adaptado de Lejeune et al., 2015.

\begin{tabular}{|c|c|c|c|c|c|}
\hline Referência & $\begin{array}{l}\text { Modelo/esquema de } \\
\text { superfície terrestre }\end{array}$ & Resolução & $\Delta \mathbf{T}$ & $\Delta \mathbf{P}$ & TSM \\
\hline Dickinson e Henderson-Sellers (1988) & CCMOB/BATS & $4.5^{\circ} \times 7.5^{\circ}$ & +3 & 0 & Fixa \\
\hline Lean e Warrilow (1989) & UKMO & $2.5^{\circ} \times 3.75^{\circ}$ & $+2,4$ & $-1,34$ & Fixa \\
\hline Nobre et al. (1991) & $\mathrm{NMC} / \mathrm{SiB}$ & $1.8^{\circ} \times 2.8^{\circ}$ & $+2,5$ & $-1,76$ & Fixa \\
\hline Dickinson e Kennedy (1992) & CCM1/BATS1e & $4.5^{\circ} \times 7.5^{\circ}$ & $+0,6$ & $-1,4$ & Interativa \\
\hline Henderson-Sellers et al. (1993) & CCM1/BATS1e & $4.5^{\circ} \times 7.5^{\circ}$ & $+0,6$ & $-1,61$ & Interativa \\
\hline Manzi (1993) & EMERAUDE/ISBA & $2.8^{\circ} \times 2.8^{\circ}$ & $+1,3$ & $-0,04$ & Fixa \\
\hline Lean e Rowntree (1993) & UKMO & $2.5^{\circ} \times 3.75^{\circ}$ & $+2,1$ & $-0,81$ & Fixa \\
\hline Dimeyer e Shukla (1994) & $\mathrm{NMC} / \mathrm{SSiB}$ & $4.5^{\circ} \times 7.5^{\circ}$ & +2 & $-0,28$ & Fixa \\
\hline Polcher e Laval (1994a) & LMD3/SECHIBA & $2.0^{\circ} \times 5.6^{\circ}$ & $+3,8$ & 1,08 & Fixa \\
\hline Polcher e Laval (1994b) & LMD3/SECHIBA & $2.0^{\circ} \times 5.6^{\circ}$ & $-0,11$ & $-0,51$ & Fixa \\
\hline Sud et al. (1996) & GLA/SSiB & $4.0^{\circ} \times 5.0^{\circ}$ & +2 & $-1,48$ & Fixa \\
\hline Zhang et al. (1996) & CCM1/BATS1e & $4.5^{\circ} \times 7.5^{\circ}$ & $+0,3$ & $-1,1$ & Interativa \\
\hline Manzi e Planton (1996) & EMERAUDE/ISBA & $2.8^{\circ} \times 2.8^{\circ}$ & $-0,50$ & $-0,04$ & Fixa \\
\hline Lean e Rowntree (1997) & UKMO & $2.5^{\circ} \times 3.75^{\circ}$ & $+2,3$ & $-0,27$ & Fixa \\
\hline Hahmann e Dickinson (1997) & RCCM2/BATS1e & $2.8^{\circ} \times 2.8^{\circ}$ & +1 & $-0,99$ & Fixa \\
\hline Costa e Foley (2000) & GENESIS/IBIS & $4.5^{\circ} \times 7.5^{\circ}$ & $+1,4$ & $-0,73$ & Interativa \\
\hline Gedney e Valdes (2000) & ECMWF & $3^{\circ} \times 3^{\circ}$ & $+1,3$ & $-0,79$ & Fixa \\
\hline Kleidon e Heimann (2000) & ECHAM & $5.6^{\circ} \times 5.6^{\circ}$ & $+2,5$ & $-0,38$ & Fixa \\
\hline Voldoire e Royer (2004) & ARPEGE/ISBAd & $2.8^{\circ} \times 2.8^{\circ}$ & $-0,10$ & $-0,4$ & Fixa \\
\hline Voldoire e Royer (2005) & ARPEGE/ISBAd & $2.8^{\circ} \times 2.8^{\circ}$ & $+0,6$ & $-0,74$ & Interativa \\
\hline Ramos da Silva et al. (2008) & GISS & $4^{\circ} \times 5^{\circ}$ & $+0,8$ & $-1,24$ & Fixa \\
\hline Nobre et al. $(2009 \mathrm{~b})$ & $\mathrm{CPTEC} / \mathrm{SSiB}$ & $1.85^{\circ} \times 1.85^{\circ}$ & $\mathrm{ni}$ & $-3,3$ & Interativa \\
\hline Medvigy et al. (2011) & OLAM & $\begin{array}{l}\sim 25 \mathrm{~km} \text { sobre a América do Sul } \\
\sim 200 \mathrm{~km} \text { diverso }\end{array}$ & $\mathrm{ni}$ & $-0,17$ & Fixa \\
\hline Costa (2016) & $\mathrm{CAM} 3.1 / \mathrm{CLM} 2.1$ & $1.4^{\circ} \times 1.4^{\circ}$ & $+0,14$ & $-0,32$ & Fixa \\
\hline Este estudo (2017) & $\mathrm{CCM} 3 / \mathrm{IBIS}$ & $\sim 2.8^{\circ} \times 2.8^{\circ}$ & $+0,28$ & $-1,03$ & Fixa \\
\hline
\end{tabular}


Foram analisadas outras variáveis meteorológicas que poderiam ajudar a explicar o comportamento da precipitação simulado pelos cenários de desmatamento. A primeira delas foi a anomalia de temperatura do ar na superfície mensal em cada um desses cenários. Os meses de setembro, outubro e novembro apresentaram as maiores anomalias positivas de temperatura do ar (Figura 9), coincidindo com o período de maiores anomalias negativas de precipitação. Na Figura 9 percebe-se que quanto maior a área desmatada, maior era a área afetada pelo aumento da temperatura, com valores de anomalia acima de $2^{\circ} \mathrm{C}$. As regiões onde as anomalias positivas de temperatura do ar ocorreram foram aproximadamente semelhantes às de ocorrência de anomalia negativa de precipitação (Figura 8). Tais alterações na temperatura e precipitação podem ser justificadas pela redução da rugosidade superficial, ocorrida com a transição de floresta para pastagem, causando diminuição no fluxo de calor latente e alterando a forma como a superfície se esfria. Além disso, a redução do índice de área foliar e da profundidade das raízes faz com que uma menor quantidade de vapor d'água seja reciclada e disponibilizada na atmosfera, limitando assim o mecanismo de evapotranspiração da área (FOLEY et al., 2003). 

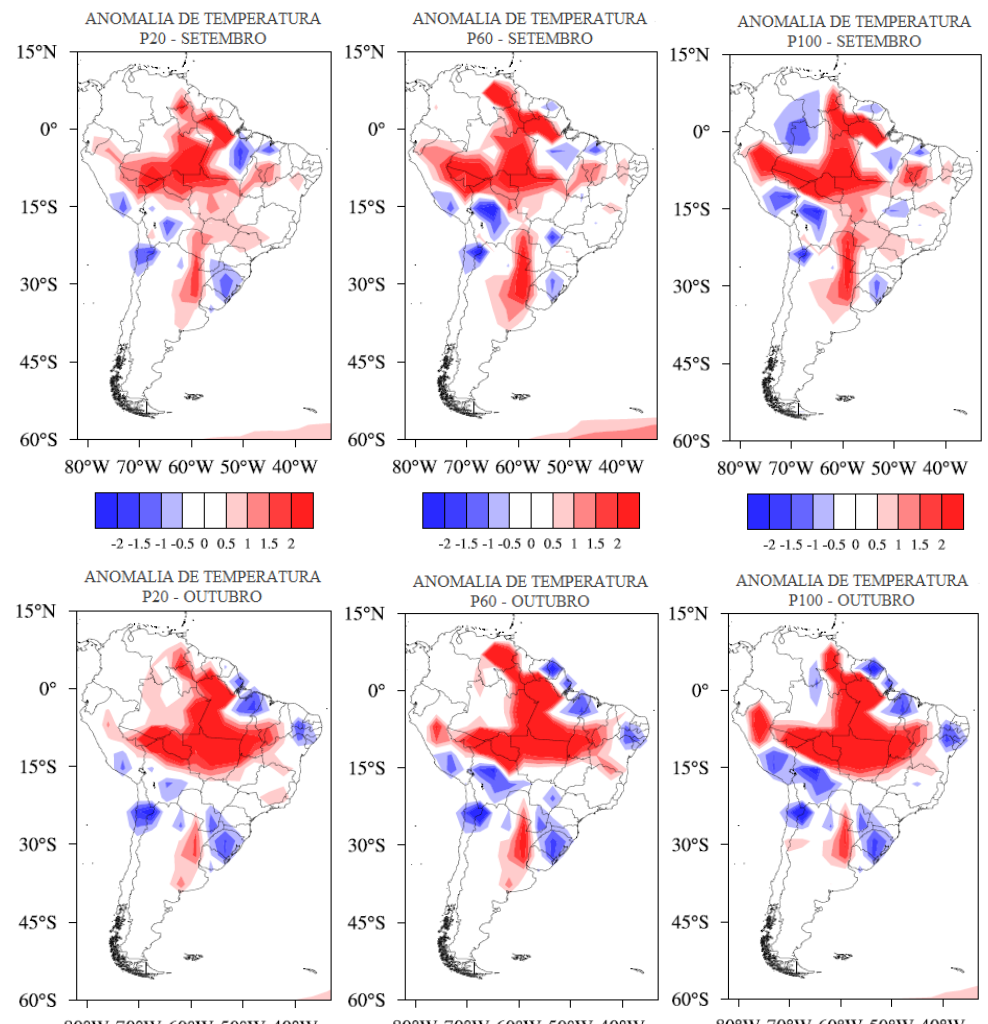

ANOMALIA DE TEMPERATURA
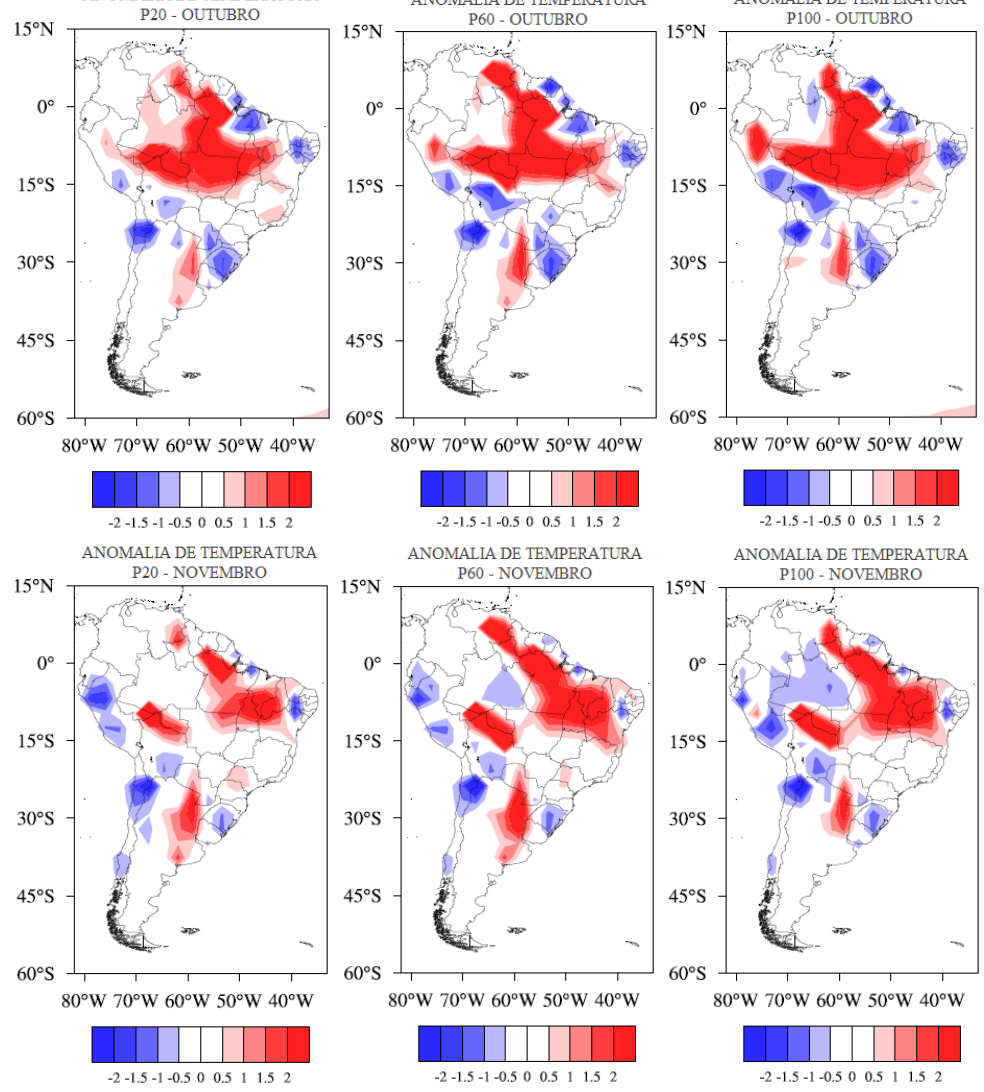

ANOMALIA DE TEMPERATURA

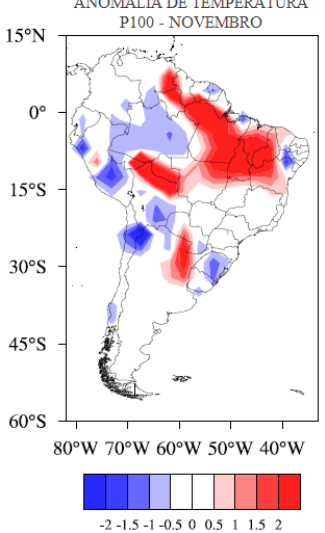

Figura 9 - Mapas de anomalia de temperatura do ar na superfície média $\left({ }^{\circ} \mathrm{C}\right)$ referente aos 50 anos de integração do modelo para os meses de setembro, outubro e novembro nos cenários P20, P60 e P100, em relação à simulação Controle.

Também foi avaliado o escoamento horizontal do ar em dois níveis da atmosfera. Em 850 hPa observou-se que no mês de outubro (Figura 10) ocorreu uma pequena variação na convergência dos ventos na Região Norte, próximo a divisa entre o Amazonas e o Pará (área dentro da elipse vermelha), sendo esta convergência menor nos cenários P60 e P100. A redução na convergência inibe a ascensão do ar, desfavorecendo assim a formação de nuvens e chuva (MENDONÇA e DANNI-OLIVEIRA, 2007). Tais fenômenos se consolidaram neste mês, coincidindo com as anomalias negativas de precipitação (Figura 8). Além disso, dentro da área da elipse preta da direita notou-se que conforme 0 
desmatamento aumentava, mais intenso esse escoamento se tornava em direção à área da elipse preta da esquerda, onde ocorreram anomalias positivas de precipitação (noroeste da América do Sul). A redução da rugosidade superficial, ocorrida com a transição de floresta para pastagem, favoreceu um escoamento horizontal mais intenso do ar, que carregava umidade do oceano Atlântico. Esse ar úmido ao encontrar com a barreira orográfica dos Andes, gerou um aumento da precipitação sobre essa região delimitada pela elipse preta da esquerda.
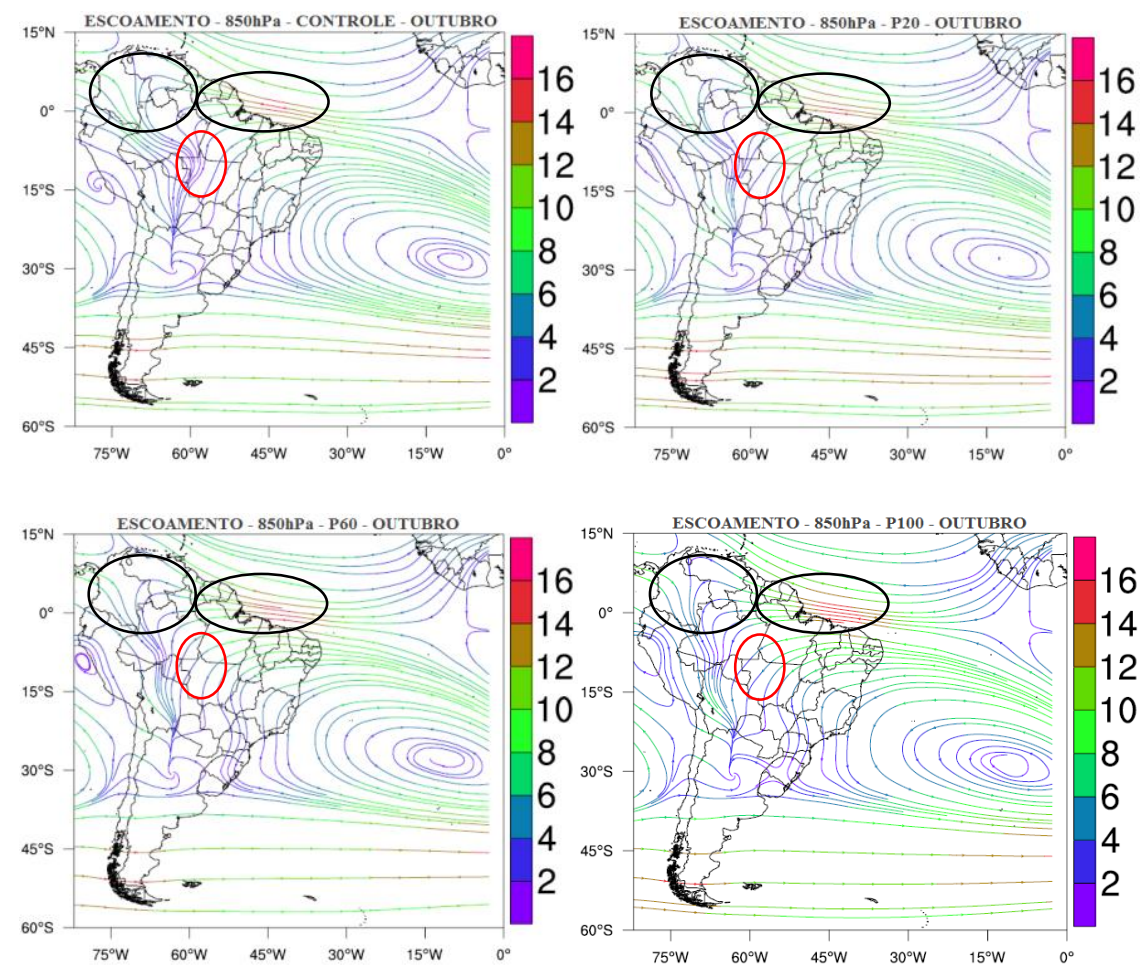

Figura 10 - Escoamento horizontal médio do ar (m/s) em 850 hPa referente aos 50 anos de integração do modelo para o mês de outubro em todos os cenários simulados.

No escoamento horizontal do ar em $200 \mathrm{hPa}$ para o mês de outubro percebeu-se a formação da Alta da Bolívia sobre o Estado de Rondônia na simulação controle, nos demais cenários de desmatamento o fenômeno também ocorreu, porém com uma vorticidade aparentemente menor, como pode ser observado nas linhas de corrente dos centros das altas da Figura 11. Comparando com os mapas de anomalia, notou-se que tal variação coincidiu com o mês de maiores anomalias negativas de precipitação. Essa redução nos totais pluviométricos também pode ser justificada pelo enfraquecimento da Alta da Bolívia, fenômeno este que colabora para a precipitação que ocorre principalmente nas regiões Centro-Oeste, Norte e parte do Nordeste do Brasil durante a primavera e verão austral (FISCH et al., 1998; FERREIRA et al., 2009; NIELSEN et al., 2018). 

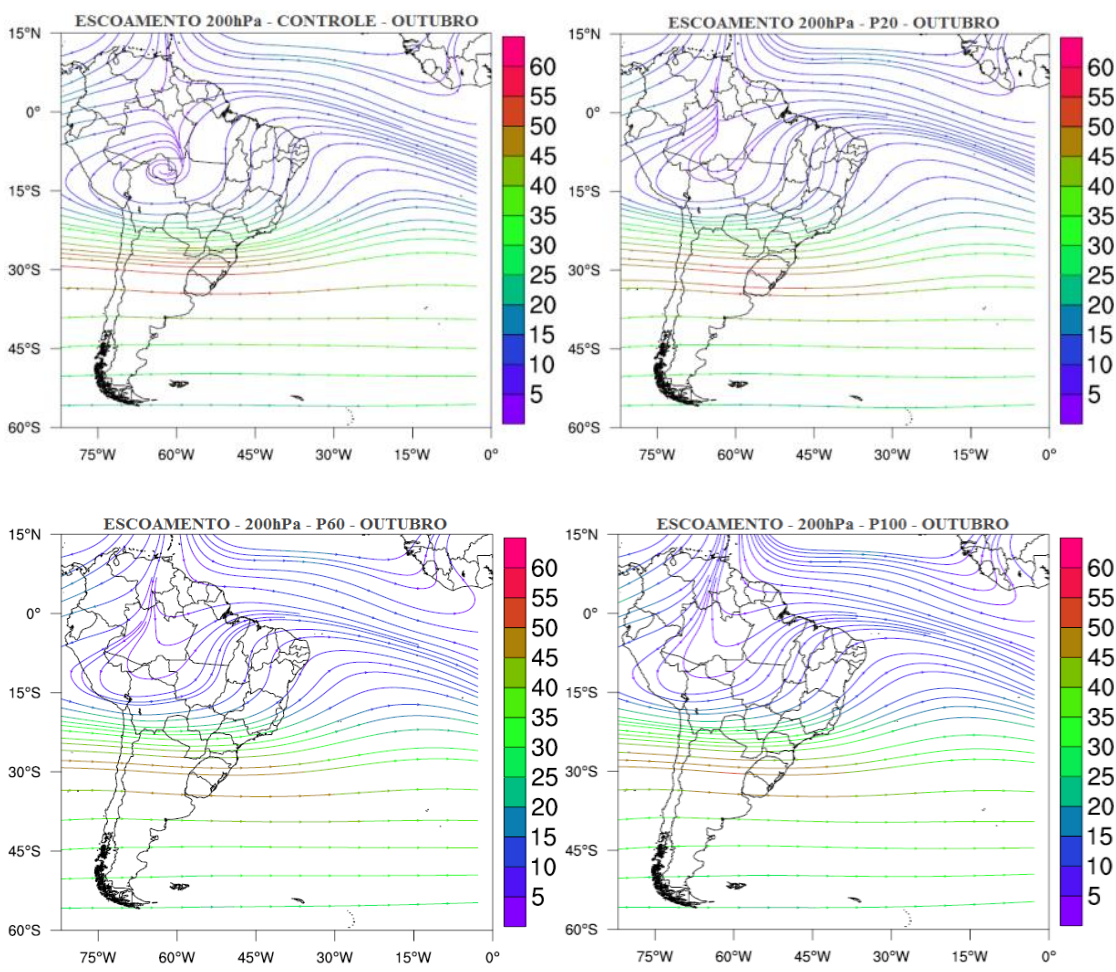

Figura 11 - Escoamento horizontal médio do ar (m/s) em $200 \mathrm{hPa}$ referente aos 50 anos de integração do modelo para o mês de outubro em todos os cenários simulados.

As alterações ocorridas na cobertura vegetal após 50 anos, também foram facilmente visualizadas na simulação que considerou $100 \%$ da cobertura inicial como floresta tropical e nos demais cenários de desmatamento, onde a floresta foi representada com cobertura inicial de $20 \%$, $60 \%$ e $100 \%$ transformada em pastagem (Figura 12). Na simulação Controle observou-se a regeneração da floresta, em especial na Região Nordeste antes ocupada por cerrado, porém não sendo muito expressiva em relação à sua extensão. Notaram-se alterações quanto às características de algumas áreas da Região Norte e Nordeste, que anteriormente possuíam floresta tropical e, posteriormente, passaram a ser cobertas por floresta decídua. No cenário P20 observou-se a regeneração da floresta sobre a maior parte da área que havia sido desmatada nas regiões Norte, Nordeste e Centro-Oeste, sendo a área regenerada por floresta decídua. O cenário P60 apresentou comportamento semelhante ao cenário P20, contudo, a extensão de floresta regenerada em 50 anos foi um pouco menor. Já no cenário P100 houve uma regeneração semelhante a do cenário P60, demonstrando que o impacto do desmatamento não foi linear, sendo a regeneração da floresta mais homogênea e gradual a partir de um percentual de desmatamento maior que $60 \%$. 


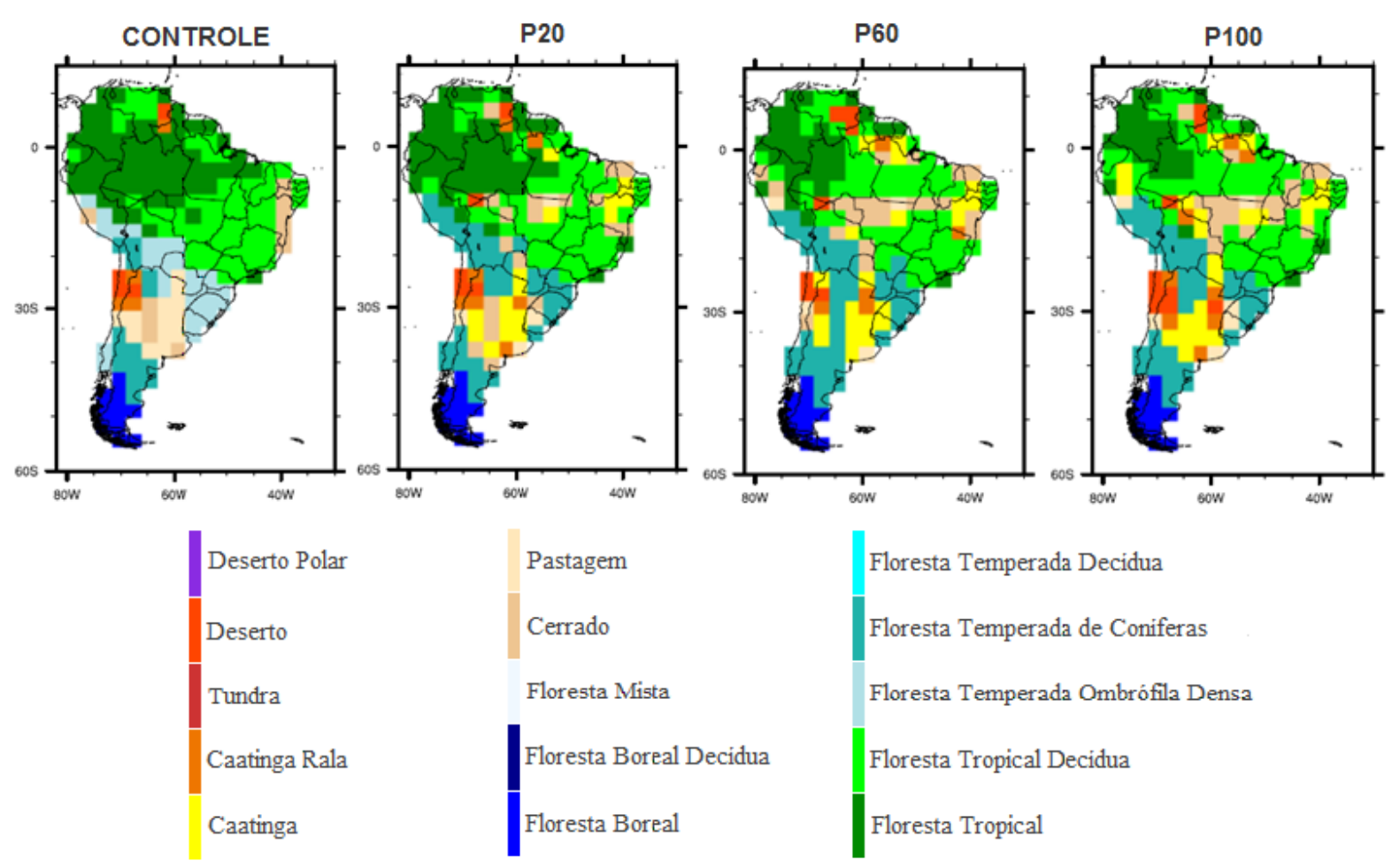

Figura 12 - Cobertura final do solo das simulações Controle, P20, P60 e P100.

\section{CONCLUSÕES}

Este estudo teve como objetivo principal avaliar os efeitos de longo prazo do desmatamento progressivo da Amazônia sobre a precipitação no Brasil, através do modelo acoplado CCM3-IBIS. Com essa finalidade, foram efetuadas quatro simulações com cenários distintos para a Amazônia, onde um considerou $100 \%$ da cobertura inicial do solo como floresta tropical e os demais consideraram $20 \%$, $60 \%$ e $100 \%$ da cobertura inicial do solo transformada em pastagem, em um período de 50 anos.

De maneira geral, nas Regiões Norte, Nordeste e Centro-Oeste prevaleceram anomalias negativas da precipitação total considerando os cenários de desmatamento amazônico. As anomalias médias mensais atingiram $-3,30 \mathrm{~mm} /$ dia no mês de outubro, $-1,26 \mathrm{~mm} /$ dia no mês de dezembro e $-2,80$ $\mathrm{mm} /$ dia no mês de outubro, considerando todas as células de grade das regiões Norte, Nordeste e Centro-Oeste, respectivamente. Entretanto, nas Regiões Sudeste e Sul prevaleceram pequenas anomalias positivas da precipitação total. As anomalias médias mensais alcançaram cerca de $0,80 \mathrm{~mm} /$ dia no mês de dezembro e janeiro para todas as células de grade das regiões Sudeste e Sul, respectivamente.

Verificou-se, também, a distribuição espacial das anomalias médias mensais de precipitação total para cada cenário de desmatamento, e os meses com anomalias mais intensas foram setembro, outubro e novembro, atingindo valores abaixo de $-8 \mathrm{~mm} /$ dia sobre a Amazônia. Tais áreas de anomalias se expandiram para regiões adjacentes e se intensificaram conforme aumentava o desmatamento amazônico, atingindo a Região Norte, oeste da Região Nordeste e norte da Centro-Oeste. Esse comportamento da anomalia de precipitação pode 
ter ocorrido devido à redução da rugosidade superficial com o desmatamento, gerando uma redução da evapotranspiração e aumentando a temperatura do ar à superfície. Além disso, observou-se uma redução na convergência dos ventos em 850 hPa sobre a região Norte, inibindo a ascensão do ar e desfavorecendo a precipitação. Em altos níveis, observou-se um enfraquecimento da Alta da Bolívia, desfavorecendo a atividade convectiva sobre as regiões Norte, CentroOeste e parte do Nordeste. Em contrapartida, observou-se que pequenas anomalias positivas de precipitação de no máximo $2 \mathrm{~mm} /$ dia se concentraram, em geral, na Região Sudeste, sul da Região Centro-Oeste e norte da Região Sul. Além disso, uma área de anomalias positivas, entre 2 e $4 \mathrm{~mm} /$ dia, ocorreu no extremo noroeste da América do Sul, principalmente durante outubro. 0 comportamento da anomalia de precipitação sobre essa região pode ser devido à redução da rugosidade superficial com o desmatamento, favorecendo um escoamento horizontal mais intenso do ar úmido oriundo do oceano Atlântico em $850 \mathrm{hPa}$. Esse ar úmido, ao encontrar a barreira orográfica dos Andes, provocaria um aumento da precipitação nessa região.

Dada à importância do assunto, sugere-se para trabalhos futuros o uso de modelos acoplados com maiores resoluções espaciais, para a obtenção de resultados mais detalhados na região de interesse. Além disso, a utilização de um modelo de vegetação dinâmica requer um maior número de variáveis e parametrizações de processos ecofisiológicos e ecoclimáticos. Portanto, trabalhos futuros que foquem na obtenção dessas variáveis para os biomas da América do Sul são muito importantes para a diminuição das incertezas da modelagem, já que a atmosfera é afetada pelos ecossistemas terrestres, e as retroalimentações que os mesmos provocam no clima não podem ser desconsideradas, conforme os resultados obtidos por este estudo.

\section{AGRADECIMENTOS}

Os autores gostariam de agradecer ao CNPq pela bolsa concedida na modalidade PIBITI-UFF. Também gostariam de agradecer à FAPERJ pela bolsa de Iniciação Científica.

\section{REFERÊNCIAS BIBLIOGRÁFICAS}

ARTAXO, P.; DIAS, M. A. F. S.; NAGY, L.; LUIZÃO, F. J.; CUNHA, H. B.; QUESADA, C. A. N.; MARENGO, J. A.; KRUSCHE, A. Perspectivas de pesquisas na relação entre clima e o funcionamento da Floresta Amazônica. Ciência e Cultura, v. 66, n. 3, p. 41-46, 2014.

AYOADE, J. O. Introdução à climatologia para os trópicos. 13.ed. Rio de Janeiro: Bertrand Brasil, 2010. 332 p.

BETTS, R.; NOBRE, C.; KAY, G.; SAMPAIO, G.; CHOU, S. Nova ciência e desenvolvimento científico. In: MARENGO, J. A.; NOBRE, C. A.; CHOU, S. C.; TOMASELLA, J.; SAMPAIO, G.; ALVES, L. M.; OBREGÓN, G. O.; SOARES, W. R.; BETTS, R.; KAY, G. Riscos das mudanças climáticas no Brasil. Análise Conjunta Brasil - Reino Unido Sobre os Impactos das Mudanças Climáticas e do Desmatamento na Amazônia, p. 31-49, 2011.

CHOU, S.; NOBRE, P. Avaliação de Modelos Globais e Regionais Climáticos. In: AMBRIZZI, T.; ARAUJO, M. (Eds.). PBMC - Painel Brasileiro de Mudanças 
Climáticas. Base científica das mudanças climáticas. Contribuição do Grupo de Trabalho 1 do Painel Brasileiro de Mudanças Climáticas ao Primeiro Relatório da Avaliação Nacional sobre Mudanças Climáticas. COPPE. Universidade Federal do Rio de Janeiro, Rio de Janeiro, RJ, Brasil, 2014, p. 278-319.

CORREIA, F. W. S.; ALVALÁ, R. C. S.; MANZI, A. O. Modeling the impacts of land cover change in Amazonia: a regional climate model (RCM) simulation study. Theoretical and Applied Climatology, v. 93, p. 225-244, doi: 10.1007/s00704-007-0335-z, 2008.

CORREIA, F. W. S.; MANZI, A. O.; CÂNDIDO, L. A.; SANTOS, R. M. N.; PAULIQUEVIS, T. Balanço de umidade na Amazônia e sua sensibilidade às mudanças na cobertura vegetal. Ciência e Cultura, v. 59, n. 3, p. 39-43, 2007.

COSTA, G. A. S. Avaliação do impacto de diferentes cenários de desmatamento na Região Amazônica sobre o clima do Brasil. Dissertação (Mestrado em Engenharia de Biossistemas). Universidade Federal Fluminense, Niterói, 126 p., 2016.

COSTA, M. H.; FOLEY, J. A. Combined effects of deforestation and doubled atmospheric $\mathrm{CO} 2$ concentrations on the climate of Amazonia. Journal of Climate, v. 13 , n. 1 , p. $18-34,2000$.

DAVIDSON, E. A.; CARVALHO, C. J. R.; VIEIRA, I. C. G; FIGUEIREDO, R. O.; MOUTINHO, P.; ISHIDA, F. Y.; SANTOS, M. T. P.; GUERRERO, J. B.; KALIF, K.; SABÁ, R. T. Nitrogen and phosphorus limitation of biomass growth in a tropical secondary forest. Ecological Applications, v. 14, n. 4, p. S150-S163, 2004.

DELIRE, C.; FOLEY, J. A.; THOMPSON, S. Evaluating the carbon cycle of a coupled atmosphere-biosphere model. Global Biogeochemical Cycles, v. 17, n. 1, 1012, doi: 10.1029/2002GB001870, 2003.

DICKINSON, R. E.; HENDERSON-SELLERS, A. Modelling tropical deforestation: a study of GCM land-surface parametrizations. Quarterly Journal of the Royal Meteorological Society, v. 114, n. 480, p. 439-462, doi: 10.1002/qj. 49711448009, 1988.

DICKINSON, R. E.; KENNEDY, P. Impacts on regional climate of Amazon deforestation. Geophysical Research Letters, v. 19, n. 19, p. 1947-1950, doi:10.1029/92GL01905, 1992.

DIRMEYER, P. A.; SHUKLA J. Albedo as a modulator of climate response to tropical deforestation. Journal of Geophysical Research: Atmospheres, v. 99, n. D10, p. 20863-20877, doi:10.1029/94JD01311, 1994.

FEARNSIDE, P. M. Desmatamento na Amazônia: dinâmica, impactos e controle. Acta Amazônica, v. 36, n. 3, p. 395-400, 2006.

FERREIRA, N. J.; RAMÍREZ, M. V.; GAN, M. A. Vórtices Ciclônicos de Altos Níveis que atuam na vizinhança do Nordeste do Brasil. In: CAVALCANTI, I. F. A.; FERREIRA, N. J.; SILVA, M. G. A. J.; DIAS, M. A. F. S. (Org.). Tempo e clima no Brasil. São Paulo: Oficina de Textos, 2009. p. 43-60.

FISCH, G.; MARENGO, J. A.; NOBRE, C. A. Uma Revisão Geral sobre o Clima da Amazônia. Acta Amazônica, v. 28, n. 2, p. 101-126, 1998.

FOLEY, J. A.; COSTA, M. H.; DELIRE, C.; RAMANKUTTY, N.; SNYDER, P. Green surprise? How terrestrial ecosystems could affect earth's climate. Frontiers in Ecology and the Environment, v. 1, n. 1, p. 38-44, 2003. 
FOLEY, J. A.; PRENTICE, I. C.; RAMANKUTTY, N.; LEVIS, S.; POLLARD, D.; SITCH, S.; HAXELTINE, A. An integrated biosphere model of land surface processes, terrestrial carbon balance, and vegetation dynamics. Global Biogeochemical Cycles, v. 10, n.4, p. 603-628, 1996.

GEDNEY, N.; VALDES, P. J. The Effect of Amazonian Deforestation on the Northern Hemisphere Circulation and Climate.Geophysical Research Letters, v. 27, n. 19, p. 3053-3056, 2000.

HAHMANN, A. N.; DICKINSON, R. E. RCCM2-BATS model over tropical South America: applications to tropical deforestation. Journal of Climate, v. 10, n. 8, p. 1944-1964, 1997.

HENDERSON-SELLERS, A.; DICKINSON, R. E.; DURBRIDGE, T.; KENNEDY, P.; MCGUFFIE, K.; PITMAN, A. Tropical deforestation: modeling local-to regionalscale climate change. Journal of Geophysical Research: Atmospheres, v. 98, n. D4, p. 7289-7315, doi:10.1029/2JD02830, 1993.

IBGE - Instituto Brasileiro de Geografia e Estatística. 2004. Mapa de Biomas e de Vegetação. Disponível em: <http://www.ibge.gov.br/home/presidencia/noticias/21052004biomashtml.shtm > Acesso em: 22 de mar. 2016.

INPE - Instituto Nacional de Pesquisas Espaciais. 2016. Projeto de Monitoramento da Floresta Amazônica brasileira por Satélite.Disponível em: <http://www.obt.inpe.br/prodes/index.php> Acesso em: 25 de mar. 2016.

KIEHL, J. T.; HACK, J. J.; BONAN, G. B.; BOVILLE, B. A.; WILLIAMSON, D. L.; RASCH, P. J. The National Center for Atmospheric Research Community Climate Model: CCM3. Journal of Climate, v. 11, n. 6, p. 1131-1149, 1998.

KLEIDON, A.; HEIMANN, M. Assessing the role of deep rooted vegetation in the climate system with model simulations: mechanism, comparison to observations and implications for Amazonian deforestation. Climate Dynamics, v. 16, n. 2-3, p. $183-199,2000$.

LEAN, J.; ROWNTREE, P.A GCM simulation of the impact of Amazonian deforestation on climate using an improved canopy representation. Quarterly Journal of the Royal Meteorological Society, v. 119, n. 511, p. 509-530, doi:10.1002/qj.497119,51109, 1993.

LEAN, J.; ROWNTREE, P. Understanding the sensitivity of a GCM simulation of Amazonian deforestation to the specification of vegetation and soil characteristics. Journal of Climate, v. 10, n. 6, p. 1216-1235, 1997.

LEAN, J.; WARRILOW, D. Simulation of the regional climatic impact of Amazon deforestation. Nature, v. 342, n. 6248, p. 411-413, doi:10.1038/342411a0, 1989.

LEJEUNE, Q.; DAVIN, E. L.; GUILLOD, B. P.; SENEVIRATNE, S. I. Influence of Amazonian deforestation on the future evolution of regional surface fluxes, circulation, surface temperature and precipitation. Climate Dynamics, v. 44, n. 9-10, p. 2769-2786, 2015.

LLOPART, M.; REBOITA, M. S.; COPPOLA, E.; GIORGI, F.; DA ROCHA, R. P.; DE SOUZA, D. O. Land Use Change over the Amazon Forest and Its Impact on the Local Climate. Water, v. 10, n. 2, p. 149, 2018. 
MANZI, A. O.; PLANTON, S. Calibration of a GCM using ABRACOS and ARME data and simulation of Amazonian deforestation. In: Gash, J. H. C.; NOBRE, C. A.; ROBERTS, J. M.; VICTORIA, R. L. (Eds). Amazonian deforestation and climate.Wiley, West Sussex, p. 505-530, 1996.

MANZI, A. O. Introduction d'un schéma des transferts sol-végétationatmosphère dans un modèle de circulation générale et application à la deforestation Amazonienne. Tese PhD, Université Paul Sabatier, Toulouse, 1993.

MARENGO, J. A.; NOBRE, C. A.; CHOU, S. C.; TOMASELLA, J.; SAMPAIO, G.; ALVES, L. M.; OBREGÓN, G. O.; SOARES, W. R.; BETTS, R.; KAY, G. Riscos das mudanças climáticas no Brasil. Análise Conjunta Brasil - Reino Unido Sobre os Impactos das Mudanças Climáticas e do Desmatamento na Amazônia, p. 1-56, 2011.

MEDVIGY, D.; WALKO, R. L.; AVISSAR, R. Effects of deforestation on spatiotemporal distributions of precipitation in South America. Journal of Climate, v. 24, n. 8, p.2147-2163, 2011.

MENDONÇA, F.; DANNI-OLIVEIRA, I. M. Climatologia: noções básicas e climas do Brasil. São Paulo: Oficina de Textos, 2007. 206 p.

NIELSEN, D. M.; BELÉM, A. L.; MARTON, E.; CATALDI, M. Dynamics-based regression models for the South Atlantic Convergence Zone. Climate Dynamics, https://doi.org/10.1007/s00382-018-4460-4, 2018.

NOBRE, A. D. O futuro climático da Amazônia. Relatório de Avaliação Científica. 2014. Disponível em: <http://www.ccst.inpe.br/wpcontent/uploads/2014/11/Futuro-Climatico-da-Amazonia.pdf> Acesso em: 06 de abr. 2016.

NOBRE, C. A.; MARENGO, J. A.; ARTAXO, P. Understanding the Climate of Amazonia: Progress From LBA. In: KELLER M.; BUSTAMANTE M.; GASH J.; DIAS, P. S. (Eds). Amazonia and Global Change. Geophysical Monograph Series, v. 186 , p. $145-147,2009$ a.

NOBRE, C. A.; SELLERS, P.; SHUKLA, J. Amazonian deforestation and regional climate change. Journal of Climate, v. 4, n. 10, p. 957-988, 1991.

NOBRE, P.; MALAGUTTI, M.; URBANO, D. F.; DE ALMEIDA, R. A. F.; GIAROLLA, $\mathrm{E}$. Amazon deforestation and climate change in a coupled model simulation. Journal of Climate, v. 22, n. 21, p. 5686-5697, 2009b.

PEREIRA, M. P. S. Interação entre ecossistemas terrestres e a atmosfera na Amazônia: conexões biogeofísicas e biogeoquímicas. Dissertação (Mestrado em Meteorologia Agrícola). Universidade Federal de Viçosa, Viçosa, 111 p, 2006.

POLCHER, J.; LAVAL, K. The impact of African and Amazonian deforestation on tropical climate. Journal of Hydrology, v. 155, n. 3-4, p. 389-405, doi:10.1016/0022-1694(94)90179-1, 1994a.

POLCHER, J.; LAVAL, K. A statistical study of the regional impact of deforestation on climate using the LMD GCM. Climate Dynamics, v. 10, n. 4-5, p. 205-219, 1994b.

RAMANKUTTY, N., FOLEY, J. A. Estimating historical changes in global land cover: croplands from 1700 to 1992. Global Biogeochemical Cycles, v. 13, n. 4, p. 997-1027, 1999. 
RAMOS DA SILVA, R.; WERTH, D.; AVISSAR, R. Regional impacts of future landcover changes on the Amazon Basin wet-season climate. Journal of Climate, $v$. 21, n. 6, p.1153-1170. doi:10.1175/2007JCLI1304.1, 2008.

SENNA, M. C. A. Capacidade de regeneração da floresta tropical amazônica sob deficiência nutricional: resultados de um estudo numérico da interação biosferaatmosfera. 139p. Tese (Doutorado em Meteorologia Agrícola). Universidade Federal de Viçosa, Viçosa, 2008.

SENNA, M. C. A.; COSTA, M. H.; PINTO, L. I. C.; IMBUZEIRO, H. M. A.; DiNIZ, L. M. F.; PIRES, G. F. Challenges to reproduce vegetation structure and dynamics in Amazonia using a coupled climate-biosphere model. Earth Interactions, v. 13, n. 11, doi: 10.1175/2009EI281.1, 2009a.

SENNA, M. C. A.; COSTA, M. H.; PIRES, G. F. Vegetation-atmosphere-soil nutrient feedbacks in the Amazon for different deforestation scenarios. Journal of Geophysical Research, 114, D4. http://dx.doi.org/10.1029/2008JD010401, 2009b.

SHEA, D. J.; TRENBERTH, K. E.; REYNOLDS R. W. A global monthly sea surface temperature climatology. Journal of Climate, v. 5, p. 987-1001, 1992.

SILVA, M. E. S.; PEREIRA, G.; DA ROCHA, R. P. Local and remote climatic impacts due to land use degradation in the Amazon "Arco of Deforestation". Theoretical and Applied Climatology, v. 125, p. 609-623, 2016.

SOARES-FILHO, B. S.; NEPSTAD, D. C.; CURRAN, L. M.; CERQUEIRA, G. C.; GARCIA, R. A.; RAMOS, C. A.; VOLL, E.; MCDONALD, A.; LEFEBVRE, P.; SCHLESINGER, P. Modelling conservation in the Amazon basin. Nature, v. 440, p. 520-523, doi: 10.1038/nature04389, 2006.

SUD, Y. C.; WALKER, G. K.; KIM, J. H.; LISTON, G. E.; SELLERS, P. J.; LAU, W. K. M. Biogeophysical consequences of a tropical deforestation scenario: a GCM simulation study. Journal of Climate, v. 9, n. 12, p. 3225-3247, 1996.

VOLDOIRE, A.; ROYER, J.F. Climate sensitivity to tropical land surface changes with coupled versus prescribed SSTs. Climate Dynamics, v. 24, n. 7-8, p. 843862, doi:10.1007/s00382-005-0014-7, 2005.

VOLDOIRE, A.; ROYER, J. F. Tropical deforestation and climate variability. Climate Dynamics, v. 22, n. 8, p. 857-874, doi:10.1007/s00382-004-0423-z, 2004.

WERTH, D.; AVISSAR, R. The local and global effects of Amazon deforestation. Journal of Geophysical Research: Atmospheres, v. 107, n. D20, p. LBA 55-1LBA 55-8, doi: 10.1029/2001JD000717, 2002.

ZARIN, D. J.; DAVIDSON, E. A.; BRONDIZIO, E.; VIEIRA, I. C. G.; SÁ, T.; FELDPAUSCH, T.; SCHUUR, E. A. G.; MESQUITA, R.; MORAN, E.; DELAMONICA, P.; DUCEY, M. J.; HURTT, G. C.; SALIMON, C.; DENICH, M. Legacy of fire slows carbon accumulation in Amazonian forest regrowth. Frontiers in Ecology and the Environment, v. 3, n. 7, p. 365-369, 2005.

ZHANG, H.; HENDERSON-SELLERS, A.; MCGUFFIE, K. Impacts of tropical deforestation. Part I: process analysis of local climatic change. Journal of Climate, v. 9, n. 7, p. 1497-1517, 1996. 